\title{
Lansia Sehat Bebas Hipertensi di Kelurahan Kenali Asam Bawah Kota Jambi
}

\author{
Maimaznah $^{1}$, Tina Yuli Fatmawati ${ }^{2}$ \\ Program Studi Diploma 3 Keperawatan, STIKes Baiturrahim Jambi \\ email: mai732373@gmail.com
}

Submitted : 15/01/2020

Accepted: 19/01/2020

Published: $31 / 01 / 2020$

\begin{abstract}
Hypertension or high blood pressure is a condition when a person experiences an increase in blood pressure either slowly or suddenly (acutely). Although the increase in blood pressure is relatively small, this can reduce life expectancy. In the United States, one in three adults suffers from hypertension, which generally does not cause complaints, even though it has been experienced for years. Target and output: The community, especially the Elderly in Kelurahan Kenali Asam Bawah, aims to increase the elderly's knowledge about the management and prevention of hypertension. This activity was carried out in the month. The implementation method included discussion and question and answer about problems related to the prevention of hypertension, giving meida education, blood pressure checking, monitoring and evaluation. Results: After the health education of the elderly understood about hypertension and out of 15 elderly people who were present, 6 elderly people were found to have blood pressure above normal (> 140/90 $\mathrm{mmHg}$ ). To the elderly who experience high blood pressure is expected to always continue to do blood pressure checks. It is expected that the community, especially RT 11 of the Kenali Asam Bawah village to maintain a healthy lifestyle
\end{abstract}

Keywords: elderly, health education, hypertension,

\begin{abstract}
Abstrak
Hipertensi atau tekanan darah tinggi merupakan kondisi ketika seseorang mengalami kenaikan tekanan darah baik secara lambat atau mendadak (akut). Meskipun peningkatan tekanan darah relatif kecil, hal ini dapat menurunkan angka harapan hidup.di Amerika Serikat, satu di antara tiga orang dewasa mengidap hipertensi, yang umumnya tidak menimbulkan keluhan, walaupun sudah dialami bertahun-tahun. Target dan luaran: Masyarakat khususnya Lansia di Kelurahan Kenali Asam Bawah,bertujuan untuk meningkatkan pengetahuan Lansia tentang penatalaksanaan dan pencegahan hipertensi. Kegiatan ini dilaksanakan pada bulan Metode pelaksanaan meliputi diskusi dan tanya jawab mengenai permasalahan yang berkaitan dengan pencegahan hipertensi,pemberian meida edukasi, pemeriksaan tekanan darah, monitoring dan evaluasi. Hasil: Setelah dilakukan pendidikan kesehatan lansia memahami tentang hipertensi dan dari 15 orang lansia yang hadir, ditemukan 6 orang lansia memiliki tekanan darah di atas normal (>140/90 mmHg). Kepada lansia yang mengalami tekanan darah tinggi diharapkan agar selalu continue dalam melakukan pemeriksaan tekanan darah. Diharapkan kepada masyarakat khususnya RT 11 kelurahan Kenali Asam Bawah agar menjaga pola hidup sehat.
\end{abstract}

Kata Kunci: hipertensi, lanjut usia, pendidikan kesehatan

\section{PENDAHULUAN}

Hipertensi atau tekanan darah tinggi merupakan kondisi ketika seseorang mengalami kenaikan tekanan darah bai secara lambat atau mendadak (akut). Meskipun peningkatan tekanan darah relative kecil, hal ini dapat menurunkan angka harapan hidup. Di Amerika Serikat, satu diantara tiga orang dewasa mengidap hipertensi, yang umumnya tidak menimbulkan keluhan, walaupun sudah dialami bertahun-tahun (Agoes, 2013).

Peningkatan kasus hipertensi juga terjadi di Indonesia. Data Riset Kesehatan Dasar (Riskesdas) tahun 2013 menunjukkan bahwa 25,8 persen penduduk Indonesia 
memiliki tekanan darah tinggi. Laporan Survei Indikator Kesehatan Nasional (Sirkesnas) menunjukkan angka pengidapnya meningkat jadi 32,4 persen. Ini artinya ada peningkatan sekitar tujuh persen dari tahun-tahun sebelumnya. Angka pasti di dunia nyata mungkin bisa lebih tinggi dari ini karena banyak orang yang tidak menyadari mereka memiliki tekanan darah tinggi. Di Indonesia setiap tahunnya terjadi 175.000 kematian akibat hipertensi dan terdapat 450.000 kasus penyakit hipertensi dari kasus hipertensi tersebut diketahui bahwa 337.500 kasus (75\%) merupakan usia produktif (15-50 tahun) yang didominasi oleh laki-laki, sisanya 112.500 kasus $(25 \%)$ tidak terdiagnosis dan baru sebagian yang tercakup dalam program penanggulangan penyakit hipertensi sesuai dengan rekomendasi WHO (Depkes RI, 2008).

Kelurahan Kenali Asam Bawah merupakan salah satu Kelurahan di Kecamatan Kota Baru Kelurahan Kenali Asam Bawah terdapat 48 RT yang terdiri dari 4739 kepala keluarga dengan jumlah penduduk 16.518 jiwa . Saat ini data yang diperoleh dari Dinas Kesehatan Kota Jambi diperoleh usia pra lansia (45-59 th) berjumlah 1579 perempuan dan 1417 lanki-laki, usia lanjut (> 60 th) berjumlah 577 perempuan dan 593 laki.-laki, usia lanjut Resiko tinggi (> 70 tahun) berjumlah 190 perempuan dan 224 laki-laki ( Data Kelurahan, 2019). Salah satu layanan kesehatan lansia yang efektif dalam memberikan pelayanan kesehatan lansia dan diselenggarakan melalui program Puskesmas adalah Posyandu Lansia.

Survei yang telah dilakukan kepada Ketua RT menjelaskan bahwa Masyarakat jarang dilakukan penyuluhan oleh Pihak Puskemas khususnya tentang penyakit hipertensi, sebagian masyarakat masih terbiasa melakukan pola hidup tidak sehat seperti kebiasaan merokok pada penduduk Pria, kurang olahraga, dan kurang memahami pola hidup sehat. Sebagian lansia masih jarang memanfaatkan pelayanan posyandu lansia sehingga lansia jarang mengontrol tekanan darahnya secara rutin di posyandu lansia.

Tujuan pengabdian ini adalah untuk meningkatkan pengetahuan lansia tentang penatalaksanaan hipertensi dan upaya pencegahan hipertensi. Oleh karena itu Tim Pengabdian melakukan pengabdian kepada masyarakat dengan mengambil judul "Lansia Sehat Bebas Hipertensi di Kelurahan Kenali Asam Bawah Kota Jambi".

\section{TARGET DAN LUARAN}

Selain luaran pada jurnal, target dalam pengabdian masyarakat ini adalah terjadi peningkatan pengetahuan peserta tentang penatalaksanaan hipertensi, pemberian media KIE (leaflet) dan pemeriksaan tekanan darah.

\section{METODE PELAKSANAAN}

Sasaran kegiatan pengabdian ini adalah lansia di RT 11 di Kelurahan Kenali Asam Bawah. Pelaksanaan pada Bulan Mei 2019. Tujuan dari pengabdian masyarakat ini diharapkan setelah mengikuti pendidikan kesehatan, lansia memahami tentang hipertensi.

Adapun metode pelaksanaan pengabdian kepada masyarakat telah dilakukan sesuai dengan rencana, diuraikan sebagai berikut :

1. Pertemuan dengan Ketua RT tentang rencana pengabdian masyarakat

2. Pada tahap Implementasi: dilakukan pendidikan kesehatan kepada lansia

3. Pemberian media KIE berupa Leaflet

4. Diskusi dan Tanya jawab mengenai permasalahan yang berkaitan dengan pencegahan hipertensi.

5. Monitoring dan evaluasi kegiatan

\section{HASIL DAN PEMBAHASAN}

Kegiatan pengabdian ini telah dilaksanakan pada bulan Mei 2019 semua terlaksana sesuai dengan rencana yang telah disusun. Kegiatan ini dibantu oleh 2 mahasiswa program studi D3 Keperawatan. 
Pada saat kegiatan dimulai lansia yang hadir mendengarkan materi yang disampaikan. Setelah itu dilakukan pengukuran tekanan darah. Dari 15 orang lansia yang hadir, ditemukan 6 orang lansia memiliki tekanan darah di atas normal $(140 / 90 \mathrm{mmHg})$ atau $30 \%$. Pada kelompok lansia yang menderita hipertensi, Pada sesi penyampaian materi, ternyata banyak lansia yang belum memahami penyakit hipertensi. Hal ini tercermin dari beberapa pertanyaan pertanyaan yang diajukan terkait dengan pencegahan hipertensi. Oleh karena itu, kegiatan semacam ini sangat diperlukan bagi masyarakat dengan materi yang menyesuaikan dengan permasalahan yang dialami oleh masyarakat di daerah tersebut. Keberhasilan pelaksanaan pengabdian kepada masyarakat dapat dilihat dari ketercapaian target yaitu adanya keterlibatan dan kehadiran lansia yang sangat antusias dalam menerima dan mengikuti penyuluhan oleh tim pengabdi.

Hipertensi, dikenal dengan istilah the silent killer atau pembunuh diam-diam karena gejalanya sering tidak disadari dan setelah komplikasi baru disadari. Penyakit ini bisa menyerang hampir setiap orang dalam berbagi kategori umur baik tua maupun muda. Seseorang bisa dikategorikan mengidap hipertensi bila tekanan darahnya lebih dari 120/80 $\mathrm{mmHg}$. Oleh karena itu, terutama bagi orang dewasa, sangat direkomendasikan untuk melakukan pengukuran tekanan darah secara rutin setidaknya setiap 1 tahun sekali atau 6 bulan sekali. Untuk membantu mengatasi hipertensi upaya yang harus dilakukan oleh lansia adalah Diet seimbang dan rendah garam, Olahraga teratur, Tidak merokok dan tidak minum alcohol, menjaga berat badan agar tetap ideal.

Evaluasi dari program kegiatan pengabdian kepada masyarakat dilaksanakan dimulai dari perencanaan, pelaksanaan dan evaluasi hasil. Adapun dokumentasi kegiatan sebagai berikut:

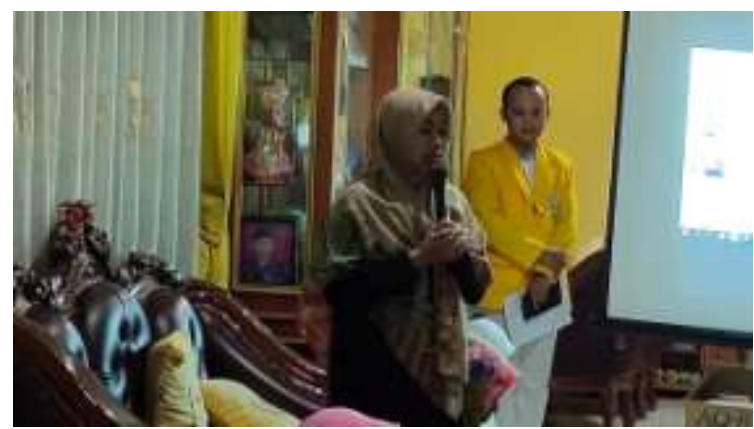

Gambar 1. Kegiatan Pendidikan Kesehatan

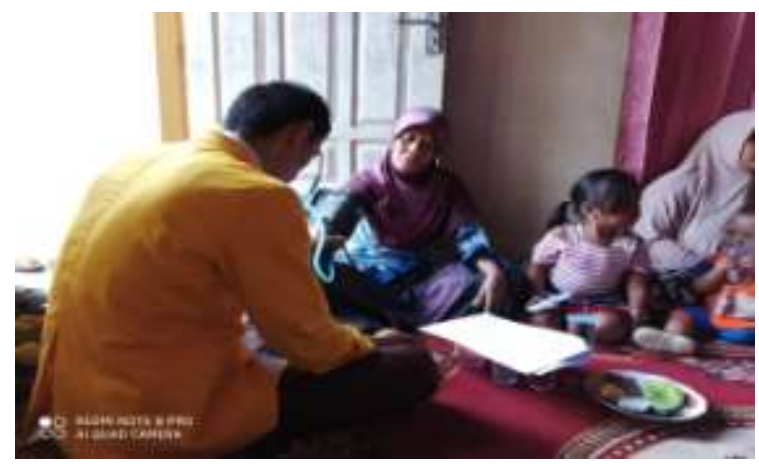

Gambar 2. Pemeriksaan Tekanan Darah

\section{KESIMPULAN DAN SARAN}

\section{Kesimpulan}

Menjaga pola hidup sehat pada setiap individu sangatlah penting guna mencegah terjadinya berbagai macam penyakit, khususnya terhindar dari serangan hipertensi. Pencegahan hipertensi dilakukan selain dengan memperhatikan pola hidup sehat seperti mengatur pola makan, tidak merokok, menghindari stress, juga melakukan aktifitas fisik. Pada kegiatan pengabdian masyarakat ini seluruh lansia yang hadir memahami tentang upaya pencegahan khususnya penyakit hipertensi.

\section{Saran}

Disarankan kepada masyarakat kelurahan Kenali Asam Bawah agar menjaga pola hidup sehat dan kepada petugas kesehatan di Puskesmas Paal 10 Agar secara continue memberikan edukasi kepada masyarakat khususnya dalam penataksanaan dan pencegahan hipertensi. 


\section{UCAPAN TERIMAKASIH}

Diucapkan terimakasihkepada:

1. Bapak lurah, bapak ketua RT 11 dan Peserta Lansia di kelurahan kenali asam bawah yang hadir pada kegiatan pengabdian masyarakat..

2. Bapak/Ibu pimpinan STIKes Baiturrahim yang memberikan dukungan moril dan materil sehingga terlaksananya kegiatan pengabdian kepada masyarakat ini.

\section{DAFTAR PUSTAKA}

Agoes, Azwar. H. 2013. Penyakit di usia tua. Jakarta; EGC

Ardiansyah. 2012. Medikal Bedah. Yogyakarta.

Depkes RI, 2008. Profil Kesehatan Indonesia. Jakarta

Lili, 2007. 100 Question \& Answers Hipertensi. PT. Gramedia. Jakarta

Rahajeng, E, 2009. Prevalensi Hipertensi dan Determinannya di Indonesia. Jakarta 